\title{
Experimental Simulation of Iron Oxide Formation on Low Alloy Steel Evaporator Tubes for Power Plant in the Presence of Iron Ions
}

\author{
Mihwa Choi and Choong Kyun Rhee ${ }^{*-}$ \\ Enwironment and Chemistry Team, Korean Electric Power Research Instinte. Daejeon $305-380$. Korea \\ -Department of Chemistry and Graduate School of Andutical Science and Technology, Chungnam National Lniversity, \\ Daejeon 305-764, Korea. "E-mail: ckrheéacnuackr \\ Received April 7, 2009, Accepted September 9, 2009
}

\begin{abstract}
Presented are the fomation of iron oxide layers on evaporator tubes in an actual fossil power plant operated under all volatile treatment (AVT) condition and an experimental simulation of iron oxide formation in the presence of ferrous and ferric ions. After actual operations for 12781 and $36326 \mathrm{hr}$ in the power plant, two iron oxide layers of magnetite on the evaporator tubes were found: a continuous inner layer and a porous outer layer. The experimental simulation (i.e., artificial corrosion in the presence of ferrous and ferric ions at $100 \mathrm{ppm}$ level for $100 \mathrm{hr}$ ) reveals that ferrous ions tum the continuous inner oxide layer on tube metal to cracks and pores, while ferric ions facilitate the production of porous outer oxide layer consisting of large cry stallites. Based on a comparison of the oxide layers produced in the experimental simulation with those observed on the actually used tubes, we propose possible routes for oxide layer fomation schenatically. In addition, the limits of the proposed corosion routes are discussed in detail.
\end{abstract}

Key Words: Corrosion. Fossil power plant. Magnetite. Ferrous ion. Ferric ion

\section{Introduction}

Spontaneous corrosion of boiler tubes in fossil power plants results in the build-up of oxide layers on the internal tube surfaces. sequential temperature rises and ultimate tube fail-

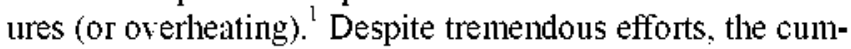
bersome corrosion of boiler tubes is inevitable due to the thermody namic instability of the main component of tubes. iron. ${ }^{2,3}$

Among various types of boilers for power plants. supercritical boilers are to generate supercritical steam to turn turbine blades. A supercritical boiler consists of a water cycle (i.e.. a water touched system) and a steam cycle (i.e.. a steam touched system).

One of the general strategies to minimize the corrosion of the water cycle in a supercritical boiler is feedwater treatment, such as all volatile treatment (AVT) and oxygenated treatment (OT) ${ }^{4}$ In AVT approach, the corrosion is controlled by adding an oxygen scavenger such as hydrazine to the feedwater to remove the dissolved oxygen which causes corrosion. ${ }^{5.6}$ In OT method. on the other hand. oxygen is fed into the feedwater for formation of passive layers of iron oxide. Although the two methods are effective in minimizing the corrosion of tube metal. the formation of corrosion products. iron oxides. spontaneously takes place on the surfaces of tube walls. The composition and growth rate of corrosion products depend on the feedwater treatment methods. In any circumstances. the iron oxides on the tube surfaces should be removed periodically by chemical cleaning to keep thermal conductivity at a proper level for prevention of ultimate boiler failure by overheating. ${ }^{1.8}$

In the water crcles of supercritical boilers operated under AVT condition, corrosion products are known to be magnetite $\left(\mathrm{Fe}_{3} \mathrm{O}_{4}\right){ }^{4 \cdot 79}$ The formation of magnetite on tube surfaces takes place in three sequential steps: formation of iron(II) hydro- vide layers. further oxidation to iron(III) hydroxide, and condensation of iron(II) hydroxide and iron(III) hydroxide to magnetite. The last step occurs rapidly at elevated temperatures. as is the case of power plant boilers. ${ }^{3}$

The oxide layers of magnetite on evaporator tubes are reported to have a double layer structure ${ }^{-3.6110}$ The inner layer. adhering to the tube metal. is compact and continuous with uniform thickness. while the outer layer, consisting of discrete magnetite crystallites. is porous. The iron atoms in the tube metal are oxidized to iron ions at the interface between the tube metal and the inner layer. ${ }^{2}$ The iron ions are neutralized by anions (e.g.. oxide ions supplied from the feedwater through the pores of the outer layer) to increase the thickness of the inner layer or diffuse out to form individual crystallites of magnetite. ${ }^{2.10}$ The two layers of magnetite on evaporator tubes play different roles: the continuous and compact inner layer protects further corrosion. while the porous outer lay'er inhibits heat transfer. $^{2}$

The aim of this paper is to demonstrate the influences of ferrous and ferric ions on the formation of iron oxides in actual and artificial corrosive mediums. The features of the oxide products formed on evaporator tubes actually employed for a supercritical boiler (regularly maintained using AVT method) were studied. In parallel. an experimental simulation, i.e. an artificial corrosion of the evaporator tube metal. was carried out in the presence of ferric and ferrous ions. By comparing the oxide layers obtained from the two different corrosion situations. it is intended to figure out their roles of iron ions in formation of iron oxide lay'ers on evaporator tubes.

\section{Experimental Section}

Characteristics of conosion products on actual evaporator tubes. The evaporator tube samples were taken from the evapo- 
Table 1. Operational specification of a supercritical boiler whose tube metal was investigated.

\begin{tabular}{ll}
\hline \multicolumn{1}{c}{ item } \\
\hline boiler type & \multicolumn{1}{c}{ specification } \\
füel & supercritical once through boiler \\
stean condition at the fünal superheater outlet & $541^{\circ} \mathrm{C}, 255 \mathrm{~kg} / \mathrm{cm}^{2}$ \\
maximum continuous rate of steam & $1,720 \mathrm{ton} / \mathrm{hr}$ \\
load & $500 \mathrm{MW}$ \\
\hline
\end{tabular}

Table 2. lngredients of $13 \mathrm{CrMo}+4$ steel, the evaporator tube metal investigated in this work (wt\%, bal. Fe).

\begin{tabular}{ccccccc}
\hline $\mathrm{C}$ & $\mathrm{Si}$ & $\mathrm{Mn}$ & $\mathrm{P}$ & $\mathrm{S}$ & $\mathrm{Cr}$ & $\mathrm{Mo}$ \\
\hline $0.10-0.18$ & $0.10-0.35$ & $0.40-0.70$ & $<0.035$ & $<0.035$ & $0.70-1.10$ & $0.45-0.60$ \\
\hline
\end{tabular}

rator in a fossil power plant operated under AVT condition. Korea. whose operational specifications are detailed in Table 1. The specific location where the samples were obtained is the middle of the evaporator whose inlet and outlet temperatures and pressures during normal operation were $308^{\circ} \mathrm{C}$ and $281 \mathrm{~kg} / \mathrm{cm}^{2}$. and $428^{\circ} \mathrm{C}$ and $264 \mathrm{~kg} / \mathrm{cm}^{2}$. respectively. (The steam condition in Table 1 is for the steam at the outlet of the final superheater.) Thus, the specimens under study are the tubes having experienced a subcritical condition. considering that the critical point of water is $225.6 \mathrm{~kg} / \mathrm{cm}^{2}$ and $374^{\circ} \mathrm{C}$. As a reference, on the other hand. the chemical composition of evaporator tube metal (DIN $13 \mathrm{CrMo44}$. Germany) is given in Table 2.

The corrosion products on actual evaporator tubes were characterized as follows. The tubes sampled from the actual boiler were cut into small test specimens ( 2 - 3 mm thick and 5 $\mathrm{cm}$ long). and then divided into two pieces to separate the hot and cold sides. The morphologies of the oxide deposits were characterized with a scanning electron microscope (SEM. Jeol JSM-6360). The cry stallite sizes were measured using an image analyzer (Leica Materials Workstation. Leica). Also. the crystallographic structures were investigated with an X-ray diffractometer (XRD, Rigaku Ultima +2200 ).

Experimental simulation of oxide formation on test specimens. The test specimens used for experimental simulation were obtained from a new tube identical to that used in the power plant. A new tube was cut into rectangular specimens $(1.99 \mathrm{~cm} \times 1.29 \mathrm{~cm} \times 0.29 \mathrm{~cm})$. The specimens were polished with $1 \mu \mathrm{m}$ diamond suspension (METADI. Buehler) and ultrasonically cleaned.

A stainless steel autoclave (Type $316 \mathrm{~L}$ ) of $120 \mathrm{~mL}$ capacity was used to induce artificial corrosion of the test specimens. A special attention was paid to the electrical isolation of the specimens from the body of the autoclave to prevent galvanic corrosion. Artificial corrosion of the specimens was performed at $350^{\circ} \mathrm{C}$. reasonably close to the actual temperature of the evaporator tube from which the specimens were taken. Also, it should be noted that it took roughly $30 \mathrm{~min}$ to reach to 350 ${ }^{\circ} \mathrm{C}$ in the specific autoclave.

The ferrous and ferric solutions of 100 ppm were prepared with $\mathrm{FeCl}_{2} \cdot 4 \mathrm{H}_{2} \mathrm{O}\left(99 \%\right.$. Aldrich) and $\mathrm{FeCl}_{3} \cdot 6 \mathrm{H}_{2} \mathrm{O}(99 \%$. Aldrich). respectively. In particular. the solution of $\mathrm{Fe}^{3-}$ ion was freshly prepared just before experiment not to reduce the $\mathrm{Fe}^{3+}$ ions to $\mathrm{Fe}_{2} \mathrm{O}_{3}$ or $\mathrm{Fe}^{\hat{2}}$ ions (absence of the presumable reduction products were confirmed experimentally). Also. it should be noted that the solutions of $\mathrm{Fe}^{2+}$ and $\mathrm{Fe}^{2+}$ ions were in equilibrium with air.

\section{Results and Discussion}

Deposits on actual boilertube. Figure I shows SEM images of the corrosion products on an evaporator tube after operating for $23+57 \mathrm{hr}$ in a supercritical boiler of a fossil power plant in Korea. Figure 1 (a) reveals that the surface is rippled and porous. As shown in Figure 1 (b). the porosity comes from the octahedral crystallites of various sizes whose comers are round. These morphological observations indicate that a flow

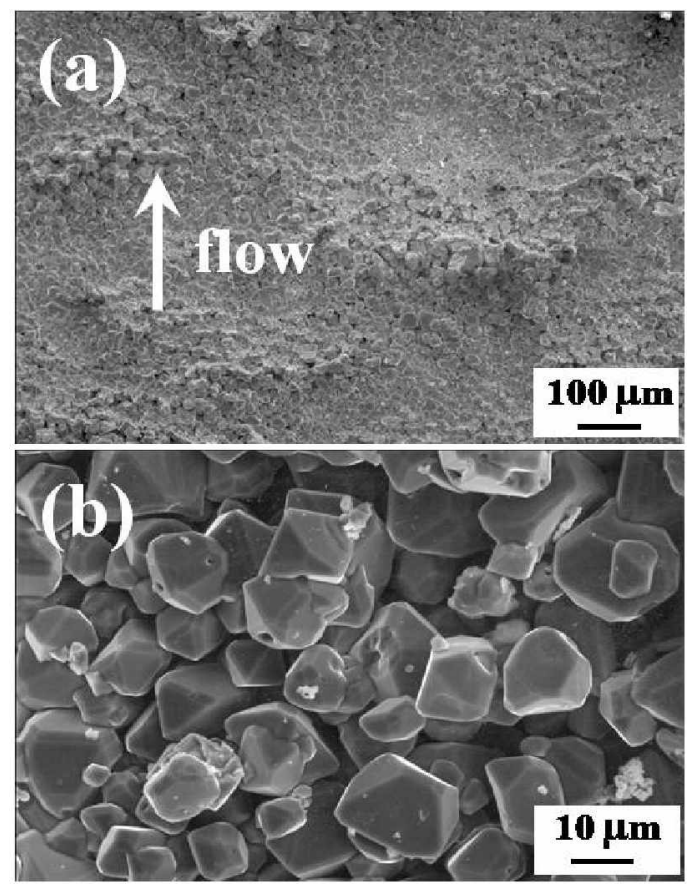

Figure 1. Micrographs of corrosion products on evaporator tubes after operating for $23457 \mathrm{hr}$ in a supercritical boiler. Magnification: (a) 100 and (b) 1000 


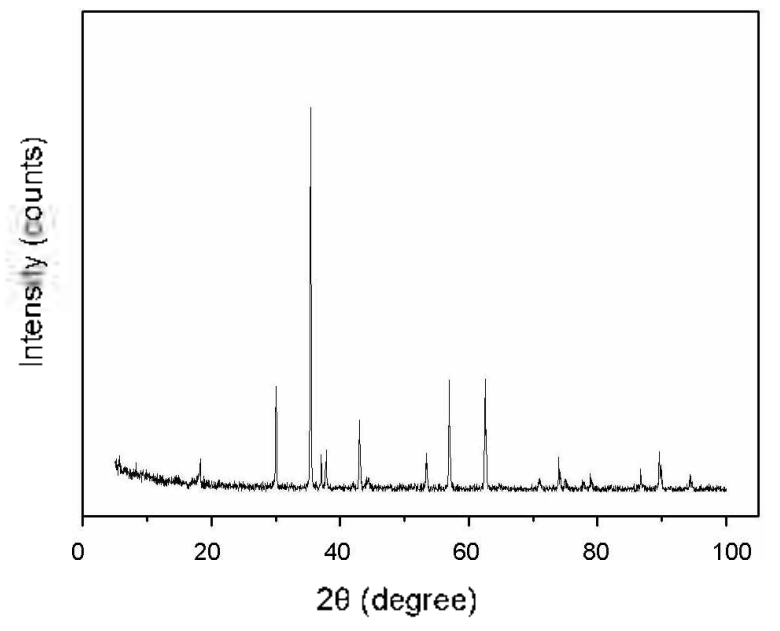

Figun 2. X-ray dilliation patten of corrosion products on a boiler watervall tubes al ter operating for $23457 \mathrm{hr}$ in a supercritical pressure boviler. The deposits were identilied to be magnetite

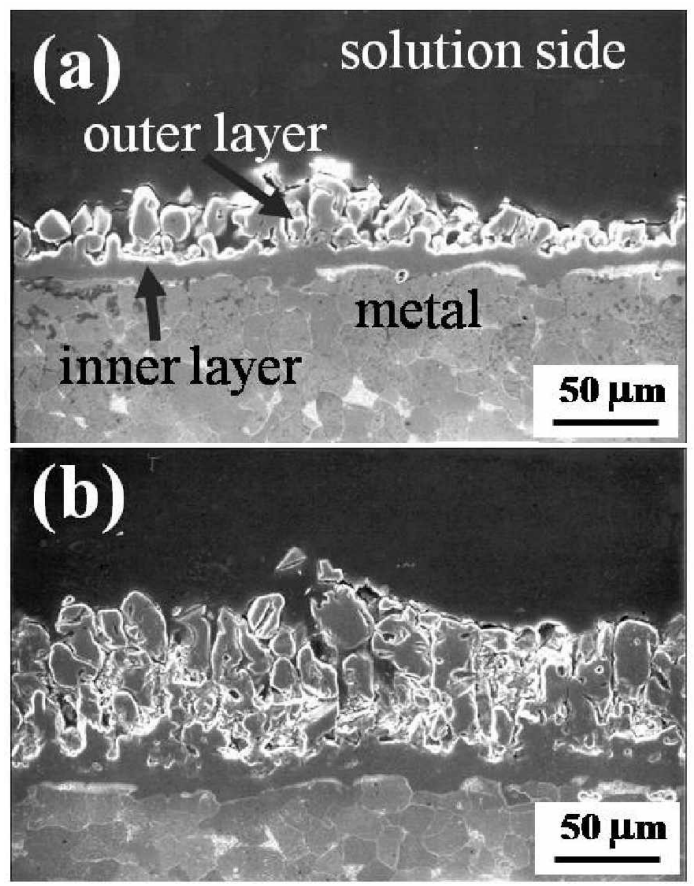

Figure 3. Cross-sections of oxide layers on an exaporator tube obtained alter (al) 12781 hr and (b) 36326 hr operation in a supereritical boiler.

of leedwater may induce culting off the sharp conners of the octahedral cry stallites by abrasion and piling up the crystallites to the ripples perpendicular to the direction of the water flow: Certainl: the ripples offer significant thow resistance, increasing boiler pressure drop in turn. ${ }^{\text {s.1.? }}$ The crystallites on the tubes were identilied with $X$-ray diffraction to be magnelite, a mixed oxide of spinel $\mathrm{FeO} \cdot \mathrm{Fe}_{2} \mathrm{O}_{3}$ (Figure 2). ${ }^{3.6}$

In Figure 3. the cross-sections of the oxide lavers on the tubes obtained after 12781 and $36326 \mathrm{hr}$ operation are compared. It is clear that there are two distinctive lavers of oxide
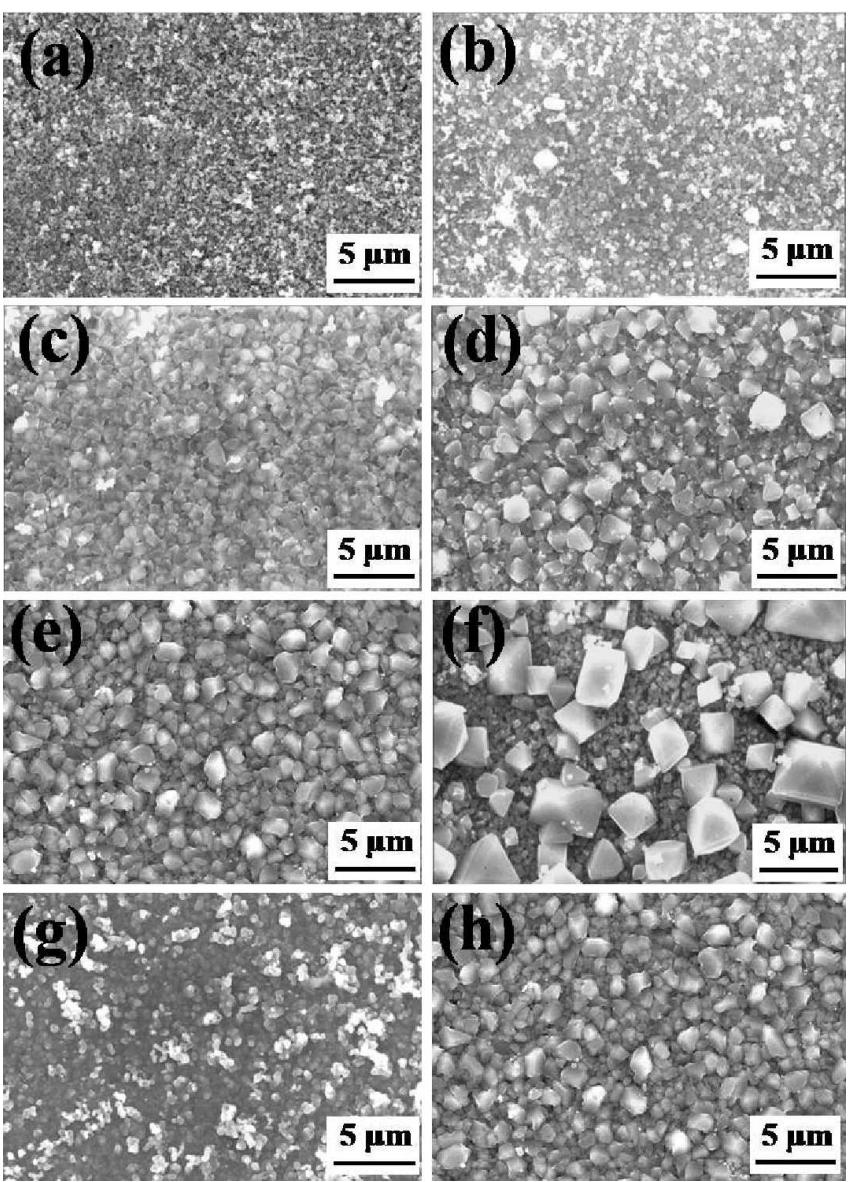

Figure 4. Micregreaphs of oxide deposits on test specimens treaded at 350 " $\mathrm{C}$ in solutions containing iron ions. The isons in the solutions and trealment times (a) $\mathrm{l}^{2} \mathrm{c}^{2}, 20 \mathrm{hr}$, (b) $\mathrm{l} \mathrm{e}^{2}, 100 \mathrm{hr}$, (c) $\mathrm{l} \mathrm{e}^{3}, 20 \mathrm{hr}$ (d)

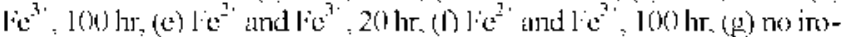
$n$ inns. 20 hr. and (h) nor iron ions, 217 hr. The concentrations of the iton ions are $100 \mathrm{pmm}$.

on the tube metal which appears in a mosaic pattern: a contimuous inner laver tenacious and adherent to the tube metal, and a porous outer laver contacting with the water side. Especially: the continuous inner laver may indicate that the inner laycr is a film of closely packed small oxide cr stallites indistinguishable with SE.M. However, the porous outer laver is certainly a loosely packed lay er of large octahedral cry stallites. The thicknesses of the two distinctive lavers depend on operation period. As the operation time increases from 12781 to $36326 \mathrm{hr}$. the thickness of the inner laver increases from $11 \mu \mathrm{m}$ to $18 \mu \mathrm{m}$, while the outer laver grows thicker from $35 \mu \mathrm{m}$ to 79 $\mu \mathrm{m}$. This specific observation supports that the growth rate of the outer layer is much higher than that of the inner laver.

Oxide formation on tube metal surface: experimental simulation. Experimental simulation, i.e. artificial corrosion of specimens under controlled conditions. was carried out to understand the roles of ferric and ferrous ions in the formation of iron oxide lavers on evaporator tubes. Because the iron ions of roughly $2-10 \mathrm{ppb}$ are reported to be produced during operation of supercritical boiler. ${ }^{13}$ it is reasonable to anticipate that ferrous and ferric ions mar affect the formation of magnetite deposits on tube metal. In actual operation of power plants. however, it 

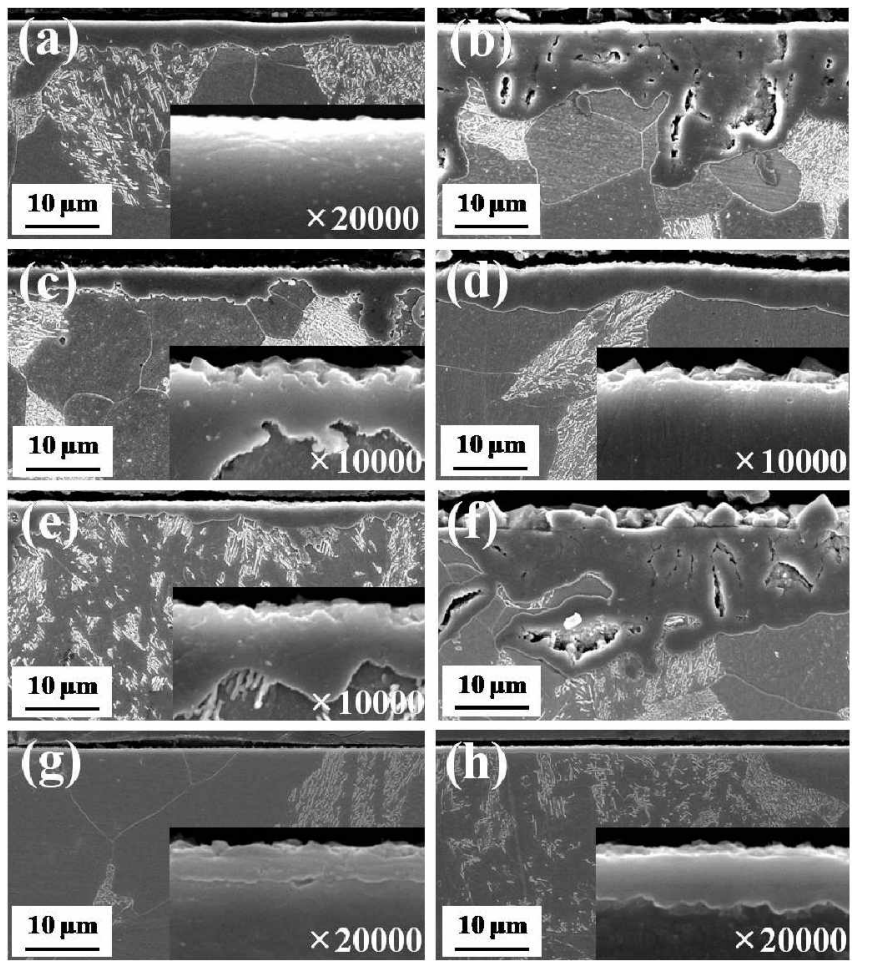

Figure 5. Cross-sections of oxide layers on the test specinens treated at $350^{\circ} \mathrm{C}$ in solutions containing iron ions. The ions in the solutions and treatment times: (a) $\mathrm{Fe}^{2-}, 20 \mathrm{hr}$, (b) $\mathrm{Fe}^{2+}, 100 \mathrm{hr}$, (c) $\mathrm{Fe}^{3-}, 20 \mathrm{hr}$, (d) $\mathrm{Fe}^{3+}, 100 \mathrm{hr}$, (e) $\mathrm{Fe}^{2+}$ and $\mathrm{Fe}^{3+}, 20 \mathrm{hr}$, (f) $\mathrm{Fe}^{\hat{*}-}$ and $\mathrm{Fe}^{3+}, 100 \mathrm{hr}$, (g) no iron ions, $20 \mathrm{hr}$, and (h) no iron ions, $217 \mathrm{hr}$. The concentrations of the iron ions are $100 \mathrm{ppmin}$. The numbers in the insets are actual magnifications.

is practically impossible to obtain specimens from a working boiler within a short time period like 100 hr after installation of new boiler tubes. Thus a mimicking experiment would be the only altemative to understand the role of the iron ions in corrosion process.

The mimicking experiment was performed in an autoclave to fonm oxide products on the test specimens at $350{ }^{\circ} \mathrm{C}$ in solutions of various compositions. A special attention was paid to insulate the specimens from the body of the autoclave to prevent electrochemical galvanic corrosion. One more point to clarify is that despite low concentration regime $(2-10 \mathrm{ppb})$ of iron ions in actual boiler water. solutions of $100 \mathrm{ppm}$ of the ions were used intentionally to reduce the experimental time scale within $100 \mathrm{hr}$.

Figure + shows SEM images of the tube metal specimens treated at $350^{\circ} \mathrm{C}$ in solutions of various compositions. In solution containing ferrous ions. oxides of fine cry stallites $(0.2$ $0.4 \mu \mathrm{m}$ ) are visible as shown in Figure 4 (a) and (b). It is also obvious that as the corrosion time increases from 20 to $100 \mathrm{hr}$. the crystallites become slightly larger. In the presence of ferric ions (Figure + (c) and (d)), on the other hand. the surface is covered with larger crystallites $(0.7-1.0 \mu \mathrm{m})$. When both ferric and ferrous ions are simultaneously in the corrosive environment. the surface morphology becomes quite different from those observed in the presence of a single iron ion. After corrosion for $20 \mathrm{hr}$. the crystallites produced in the presence of
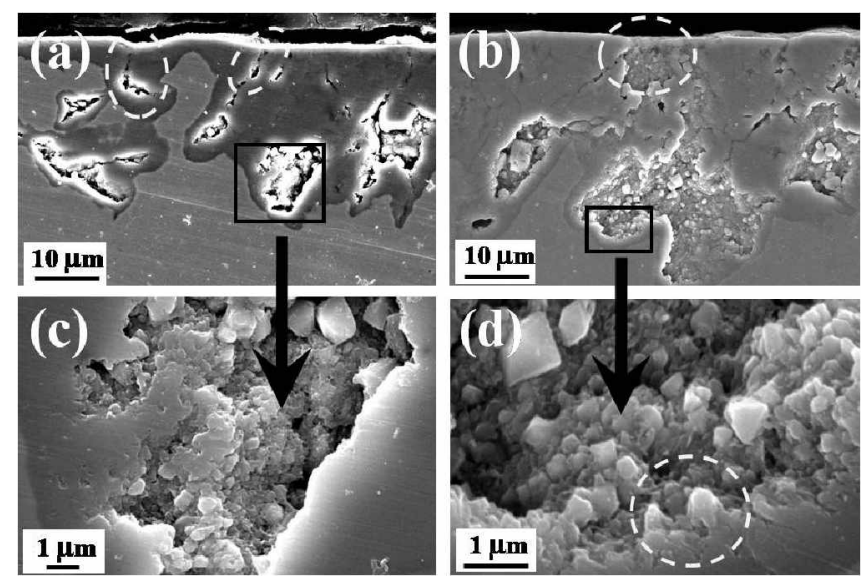

Figure 6. Details of the pores in continuous oxide layers fonmed in the presence of ferrous ions after $100 \mathrm{hr}$ treatment.

both iron ions are quite homogenous and their sizes are around $0.6 \mu \mathrm{m}$ (Figure 4 (e)). As the time increases to $100 \mathrm{hr}$. however. the surface is filled with the crystallites of two significantly different sizes: the large one is approximately $2 \mu \mathrm{m}$ and the small one is roughly $0.5 \mu \mathrm{m}$ (Figure 4 (f)). Thus, it is clear that ferrous and ferric ions are relevant to small crystallites and large crystallites, respectively. Also. a simultaneous presence of ferrous and ferric ions may provide a synergic effect to produce extremely large crystallites as shown in Figure $+(f)$. Figure $4(\mathrm{~g})$ and (h) indicate that even in the absence of the iron ions. the corrosion proceeds to show cry stallite deposits on the surface of the specimen. sinular to but slightly different from the case of ferric ion. This particular observation supports that the iron ions. probably dissolved from the tube metal, are involved in the formation of oxide layer.

The cross-sectional structures of the oxide layers on the test specimens formed under various corrosive environments are compared in Figure 5. The oxide layer produced after corrosion for $20 \mathrm{hr}$ in the presence of ferrous ions (Figure 5 (a)) is continuous and uniform in thickness $(3.5 \pm 0.9 \mu \mathrm{m})$. As the corrosion continues for $100 \mathrm{hr}$. the oxide becomes thicker and the phase boundary between the oxide layer and the tube metal is not parallel to the surface any more as shown in Figure 5 (b). Here, it is interesting to recognize that there are the pores in the oxide layer in Figure 5 (b), not observed in the actual evaporator (see below). The oxide layers formed in a solution containing ferric ions (Figure 5 (c) and (d)), especially for $100 \mathrm{hr}$, are different from those produced in the presence of ferrous ions. The thickness of the oxide layers after $20 \mathrm{hr}$ corrosion $(4.8 \pm 1.6 \mu \mathrm{m})$ in the presence of ferric ions is rather similar to that in the presence of ferrous ions (Figure 5 (c) versus Figure 5 (a)). The oxide layer having experienced a treatment for 100 $\mathrm{hr}$ is not thick as much as that in the solution of ferrous ion (Figure 5 (d) versus Figure 5 (b)). In addition, the oxide layer in Figure 5 (d) is continuous without any pore. When ferrous and ferric ions are in the corrosive medium sinultaneously. the observed features are different from those obtained in the previous cases. Specifically the thickness of the oxide layers after a $20 \mathrm{hr}$ treatment is $3.2 \pm 1.4 \mu \mathrm{m}$ (Figure 5 (e)), which close enough to those observed on the other layers in the presence of 

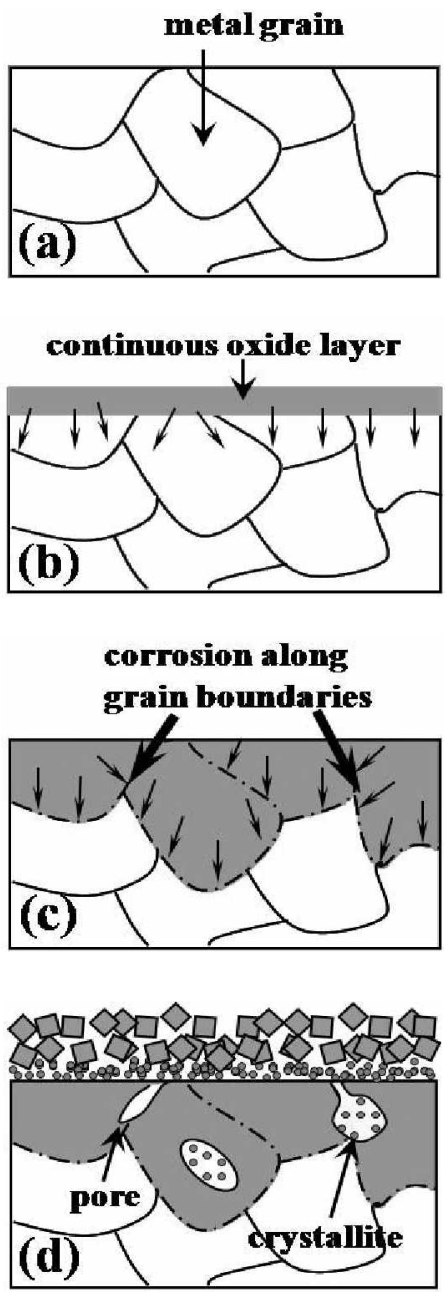

Figure 7. A schematic depicting a possible route to formation of pores and cracks in the test specimens: (a) a specimen consisting of metal grains before corrosion, (b) formation of a continuons oxide with a uniforn thickness over all the metal grains exposed to solution, (c) propagation of continuous oxide layer through grains (thin anows) followed by further conrosion along grain boundaries (thick arrows), and (d) formation of cracks and pores with small octahedral crystallites.

ferrous or ferric ions. However, a thick oxide layer with irregular phase boundary and pores is discernible again as shown in Figure 5 ( $\mathrm{f}$ ). On the other hand, the thicknesses of the oxides in Figure $5(\mathrm{~g})$ and $(\mathrm{h})$ are $0.5 \pm 1.4$ and $0.8 \pm 0.2 \mu \mathrm{m}$, respectively. supporting that the absence of the iron ions results in a very thin oxide layer. Thus, it is clear that the presence of any iron ions, regardless of their kinds. facilitates the formation of continuous oxide layers within $20 \mathrm{hr}$. Because the thick oxide layers with an irregular boundary are observed only in the presence of ferrous ion. however. it is confirmative that ferrous ion is related to the growth of continuous inner oxide layer with pores and the production of small crystallites. while ferric ion is associated with the formation of loosely packed porous outer layer consisting of large crystallites. In addition the simultaneous presence of ferrous and ferric ions in the corrosive environment is strongly correlated to the observation of very large crystallites of iron oxide (Figure 4 (f) and Figure 5 (f)). One more point to underscore is that although not shown here. the
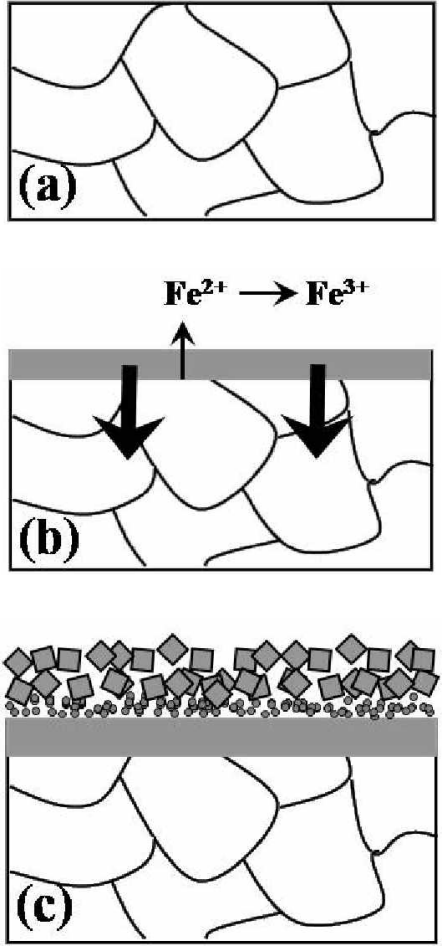

Figure 8. A schematic illustrating the corrosion process occurring on an actual evaporator tube metal: (a) an evaporator tube betore corrosion, (b) tomation of a continuous oxide with a unitom thickness and (c) fomation of octahedral crystallites on the surface of the oxide layer.

crystallographic structures of the oxide layers are magnetite.

Figure 6 shows details of pores in a continuous oxide layer formed in the presence of ferrous ions. In the top panel of Figure 6. two distinctive regions are clearly visible: one is an oxide layer (darker region in contrast) with pores and cracks. and the other is a metallic region featured with straight lines. Interestingly, the cracks in the oxide layer are connected to the surface (the ovals in Figure 6 (a)), and a certain pore shows a very wide entrance to the surface (the oval in Figure $6(\mathrm{~b})$ ). As shown in the bottom panel of Figure 6 (the rectangular areas in the top panel are zoomed), there are octahedral crystallites inside the pores. Furthermore. it is recognizable that small crystallites $<<$ $1 \mu \mathrm{m})$ come out of the continuous oxide layer (the circle in Figure 6 (d)). indicating that the continuous oxide layer transforms to small crystallites.

In Figure 7, a schematic is proposed to depict a possible route to the formation of pores and cracks in the test specimen in the presence of ferrous ions. The surface region of a test specimen consists of metal grains which are random in size and direction (Figure 7 (a)). As corrosion proceeds rapidly in the presence of any iron ions in solution for a short time such as 20 hr. the surface region of the tube metal is oxidized to transfonm to a continuous and compact layer of magnetite with a fairly uniform thickness over all the metal grains contacting with the solution (Figure 7 (b)). With further corrosion assisted by ferrous ions. the continuous oxide layer propagates fast within each grain as indicated with the arrows in Figure 7 (b). However. if the grain boundaries are barriers to hamper or prolibit 
the propagation of continuous oxide region across them, then the phase boundary between the metal and the contimuous oxide would be irregular as illustrated in Figure 7 (c). Indeed. continuous oxide layers with irregular phase boundaries are observed when further corrosion for $100 \mathrm{hr}$ is carried out in the presence of ferrous ion (Figure 5 (b) and (f)). Along the grain boundaries in the continuous oxide layer. on the other hand a dissolution or corrosion reaction would take place. If it is the case (Figure 7 (c)), then a certain reaction would proceed along the grain boundaries to form cracks as observed in Figure 6 (a). Once cracks are formed, further corrosion inside the cracks. probably accompanied with a solution supply from the outside. makes the cracks evolve to pores nucleating small octahedral cry'stallites inside them (Figure 7 (d)). Thus, the corrosion of a continuous oxide layer to a porous oxide layer takes place at the interfaces between the continuous oxide layer and the solution (e.g.. inside pores and on the surfaces of boiler tubes).

Figure 8 is a proposed schematic to illustrate the corrosion process occurring on tube metal in the actual power plant. In a certain situation of power plant operation. the metal surface (Figure 8 (a)) corrodes to produce iron ions. so that a continuous oxide film of a uniform thickness is formed as displayed in Figure 8 (b). Because the concentration of iron ions in the actual situation (2 - $10 \mathrm{ppb})$ is extremely lower than that in the experimental simulation condition ( 100 ppm), however. a continuous oxide layer would grow very slowly with a uniform thickness. On the evaporator tubes used in the actual power plant indeed. a continuous oxide layer with irregular phase boundary or with pores and cracks was not observed at all. Only on the surfaces of evaporator tubes, the corrosion of the continuous oxide results in nucleation of small crystallites and further transformation to large octahedral crystallites of magnetite as illustrated in Figure 8 (c).

The differences between the actual operating condition of power plants and the experimental simulation are the concentrations of ferrous and ferric ions and corrosion time. In the experimental simulation of high concentrations of iron ions. the oxide layer grows very fast. so that cracks and pores are formed within $100 \mathrm{hr}$ experimental time scale. especially in the presence of ferrous ion. In contrast. under the actual situation of a prolonged operation (tens of $1000 \mathrm{hr}$ experimental time scale), the growth of the continuous oxide layer is slow due to the low concentrations of iron ions. not to produce cracks and pores. The results presented in this work clearly demonstrate that the concentrations of iron ions determine the growth rate of continuous oxide layer: the higher. the faster. Here it could be assumed that there might be the maximum propagation rates at which a contimuous oxide phase is allowed to propagate through the interior of a metal grain and across the grain boundary. As discussed previously regarding Figure 7, the maximum propagation rate for a continuous oxide phase to cross a grain boundary would be much lower than that to grow through the interior of a metal grain. If a growth rate at a high concentration of ferrous ion as in the experimental simulation is higher than the maximum propagation rate across a grain boundary but lower than that through a grain interior. then the apparent growth rate within a grain would be faster than that across a grain boundary. As a result. irregular phase boundaries as in
Figure 5 (b) and (f) are formed. On the other hand, when a low growth rate as in the actual operation does not exceed the maximum propagation rate of a grain boundary. an oxide layer propagates uniformly throughout the interior of a grain and across grain boundaries. This is the exact case of Figure 3. Once a continuous oxide layer is formed. further corrosion (i.e.. oxidation of ferrous ion to ferric ion at the interface between the oxide layer and the solution) induces nucleation and growth of octahedral crystallites inside pores (via cracks) and on tube surfaces.

A few remarks on the limits of the experimental simulation. Certainly, it is worthy to note some remarks on the limits of the proposed schematics. possibly stenuming from a few differences in the conditions of the actual operation and the experimental simulation.

It is well known that during the initial startup of the boilers for power plants. iron concentration becomes very high (around $70 \mathrm{ppb}$ ). ${ }^{1.15}$ Thus. a standard operation procedure tells that boilers should be fired after the concentration of iron ions in the feedwater reaches to a concentration below $30 \mathrm{ppb} .{ }^{14} \mathrm{How}$ ever. it is also true that at the initial procedure. a feedwater of $60-70^{\circ} \mathrm{C}$ is allowed to flow for tens of hours nomally without igniting the boiler until the concentration of iron ions becontes below $30 \mathrm{ppb}$. Thus, considering the operation of a boiler for $36000 \mathrm{hr}$ as in Figure 1, the initial high concentration of iron would not be a major concern in formation of iron oxide layers on actual evaporator tubes. Furthermore. the concentration of iron ions in the sinulation experiment ( $100 \mathrm{ppm})$ is nuch ligher than the initial concentration before ignition of fire in a boiler (70 ppb). so that the high concentration in the initial startup is meaningless in the artificial corrosion of this work. However. there is still a significant concentration gap $(10$ ppb versus 100 $\mathrm{ppm}$ ), inevitable to reduce the experimental time.

Another aspect concerning the limits is that due to the high concentrations of iron ions in experimental sinulation. the condensation of iron ions to iron oxides from the solution phase would be conceivable even below $350^{\circ} \mathrm{C}$. If so. the presumable layers due to the formation of iron oxides from the solution phase in the experimental simulation would be similar to the outer layer originating from the corrosion in the actual evaporator. because the porous outer layers are relevant to the presence of iron ions in solution phase. In reality. however, the observed porous outer layers show a clear dependence on the experimental condition (Figure 4 and 5). Thus. we believe that the formation of iron oxides from the solution plase would be negligible. even though possible.

A concen regarding the presence of chloride ions in experimental solution may be raised. One may expect that the chloride ions play a role in corrosion of evaporator tubes. It has been known that an accidental inflow of sea water into a boiler water system results to local formation of iron corrosion products containing chloride." Although not shown here, an X-ray analysis of the inner and outer layers produced in the experimental simulation indicates that the concentration of cluloride was below detection limit (i.e. $<0.1 \%$ ). Thus. it is safely concluded that the chloride ions rarely affected the formation of the iron oxide layers.

The presence of water flow in the actual boiler should be 
discussed also. The corrosion medium containing iron ions is stagnant in the experimental simulation. while the feedwater flows in the actual evaporator. Certainly the flow of boiler water accelerates corrosion of evaporator tubes for fossil power plants by dissolving the protective magnetite layers to soluble ferrous ions. "Taking into account that the solubility of ferrous hydroxide is maximized at $150^{\circ} \mathrm{C}$ and steeply dropped to the solubility of magnetite between 200 and $250^{\circ} \mathrm{C}$ under an AVT condition. "the flow-accelerated corrosion in the actual evaporator would be minimal. although it takes place as hinted by the ripples in Figure 1.

As exemplified previously. the corrosive environment of the experimental simulation is not exactly identical to the corrosive environment which the actual evaporator tubes have experienced. For the specific reason the oxide layers produced in the experimental simulation are not identical to the oxide layers formed in the actual evaporator. However. it is clear that ferrous and ferric ions do important roles in the continuous oxide layer formation, especially in terms of its phase boundary shape. Also, it should be noted that the schematics proposed in this work deserves a further quantitative research.

\section{Conclusions}

The presented results reveal the roles of ferrous and ferric ions in the formation of magnetite oxide lay'ers on evaporator tubes employed in actual power plants. Ferrous ions facilitate the formation of continuous oxide layer on tube metal. while ferric ions assist the production of the porous oxide layer consisting of large crystallites. A comparison of the oxide layers obtained in the experimental simulation with those observed on the actual evaporator demonstrates that ferrous ion determines the growth rate of the continuous oxide layer, thus the shape of the phase boundary between the metal and the continuous inner layer. Based on this specific observation, we propose corrosion routes to explain schematically how the two oxide layers on exaporator tubes build up. The limits of the proposed routes coming from the differences in the conditions of the actual operation and the experimental simulation. have been discussed in understanding the corrosive formation of iron oxides in the real world.

\section{References}

1. Iwata, O: Kobayashi, N.: Misaka, Y: Mori. T: Okasaki, M.: Sanda, K. Suzuki, T; Tanaka, C.; Watanabe, T. Kurta Hondbook of Water Treament. Kurita Water Industries Ltd.: Tokyo, 1985: p 357 .

2. Mant, E. C. Potter, G. M. W. 1st hit. Congress on Metalic Corrosion 1961, 8, 417 .

3. Heitmant, H. G. Handbook of Power Plant Chentsty, CRC Press, Inc.: New York, Boca Raton, Florida, U. S. A., 1993; p 376-379.

4. Ranjbar, K. Engineening Failuw Analvis $\mathbf{2 0 0 7}, 1+620$.

5. Matsubara, M.; Itaba, S.; Miyajima, M. Powerplant Chemistry $2006,8,203$

6. Bomak, W. E. Comrosion $1988,4+154$.

7. Pieper, B. IGB Kroftwerkstechilk 1996, 76, 383

8. Tain, P.: Bhakta, U. C. Powerplant Chemistry 2007, 9, 746.

9. Ghanem, W. A; Bayyoumi, F. M; Ateya, B. G. Conrosion Science 1996, 38, 1171 .

10. Elisabeth, M. F.; Holmes, D. R. Corrosion Science 1965, 5, 362.

11. Dooley, R. B.; McNaughton, W. P. Boilerand Heat Recoven Steam Generator Tube Failures: Theon and Practices Fol. 1; Electric Power Research Institute: California, 2007; p 6-5, p 13-3.

12. Bartholomew, R.; Cline, D.: Hull, E; Shields, K.; Siegmund, T.: Yorgiadis, S. Guidelines for Chemical Cleaning of Conventional Fossil Plant Equipntent; Electric Power Research Institute: California, 2001; p l-11.

13. Dooley, R. B.; Ball, M.: Bursik, A.: Ionas, O.; Pocock, E. J.: Rice. T. K. Selection and Optimization of Boiler Water and Feedwater Theatments for Fossil Plants; Electric Power Research Institute: Cálifonia, 1997; p 3-5.

14. Dooley, R. B. Cvcling, Stantsup, Shutdown, and Lavup Fossil Plant Cycle Chemisty Guidelines for Operators and Chemists; Electric Power Research Institute: Califonia, 1998; p 64, 6-6.

15. Dooley, R. B. Cucle Chentistry Guidelines for Fossil Plants: Otygenated Treatment; Electric Power Research Institute: Califonia, 2005: p 2-

16. Robert D. P.; Harvey, M. H. The Nalco Guide to Boiler Failure Analvsis: MacGraw-Hill, Inc: New York, 1991: p 81-82.

17. Dooley, R. B.; Chexal, V. K. Intentional Joumal of Pressume Iessels and Piping 2000, 77, 87. 